U.S. Department of Commerce, National Bureau of Standards

RESEARCH PAPER RP702

Part of Journal of Research of the National Bureau of Standards, volume 13 August 1934

\title{
A BRIGHTNESS METER FOR LUMINOUS PREPARATIONS
}

\author{
By L. F. Curtiss
}

\section{ABSTRACT}

A small portable brightness meter built on the principle described by Crawford, J.Sci.Inst. 11,14(1934); has been designed for determining the brightness of luminous preparations. The instrument measures brightnesses from 2 to 75 $\mu \mathrm{L}$, using a milliammeter with a full scale reading of $10 \mathrm{ma}$. Operated from 2 dry cells, the apparatus is entirely self-contained.

\section{INTRODUCTION}

Tests of samples of luminous material for brightness are usually made with the luminous powder in the dry state. These samples are most frequently in the form of stoppered glass tubes, 5 to $8 \mathrm{~mm}$ in diameter containing a gram or so of the powder. The brightness of these preparations ranges from 5 to $30 \mu \mathrm{L}$. To cover this range by the method of varying the brightness of a comparison screen by changing the distance of a standard lamp on a track requires a track about $2 \mathrm{~m}$ long and the apparatus occupies considerable space. This note describes an application to this problem of the brightness meter developed by Crawford. ${ }^{1}$ This results in an instrument of small size and weight which is convenient to use and is readily portable.

\section{DESCRIPTION OF INSTRUMENT}

In the instrument designed by Crawford the variation of brightness is produced by changing the current through a lamp which is placed in $1 \mathrm{arm}$ of a wheatstone bridge circuit, the other $3 \mathrm{arms}$ of which have fixed resistances. A milliammeter connected between the balance points of the bridge reads the out-of-balance current of the bridge due to changes of resistance of the lamp as the applied voltage is changed. In applying this arrangement to the problem under dis-

1 Crawford, B. H., J.Sci.Inst., 11,14 (1934). 
cussion it is necessary to determine a combination of resistances, which will give suitable readings on a milliammeter to cover the

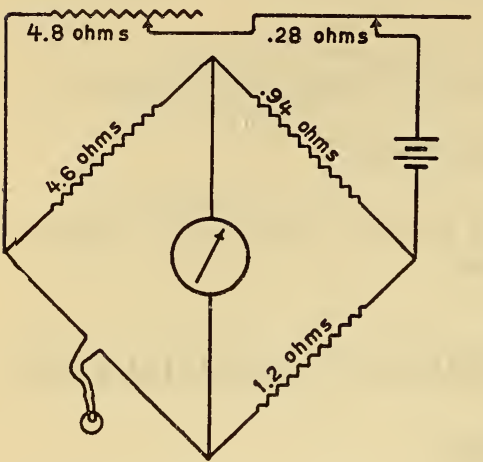

FIGURE 1.-Wiring diagram of wheatstone bridge circuit. range of brightnesses involved. An additional factor is the color filter required to correct the color of the comparison surface to agree with that of the luminous preparation.

As the actual selection of values for these components is somewhat more difficult than might appear from a casual consideration, complete details are given of the arrangement which has been found to be satisfactory. This should render the duplication of the apparatus possible with only slight adjustments of the fixed resistances.

Although the departures from Crawford's arrangement are of a minor nature, they entail the use of quite different values of resistances and voltage as well as the use of a meter of lower sensitivity. The problem was approached by first choosing a lamp and color filter. Since they are always readily available, a 3 -cell flashlight lamp (trade number 13) was selected. This also makes it possible to operate the device from dry cells or even flashlight cells, so that it will be readily portable. The resistances which were found to give suitable deflections when a 10-ma meter was used and the voltage supplied by 2 dry cells are recorded in the diagram, figure 1 , which shows the complete electrical circuit of the instrument.

The color filter used was made up of a piece of opal glass about $1 \mathrm{~mm}$ thick and a piece of a Corning green railway-signal roundel having a transmission of approximately 140 percent on the American Railway Association scale. This combination gave a brightness of the opal glass of about $2 \mu \mathrm{L} / \mathrm{ft}-\mathrm{c}$ on the green side of the filter.

The relative positions of the photometer cube, lamp, filter, and luminous preparation are shown in figure 2. The glass tube containing the luminous sample is placed in the receptacle $R$ at the top of the tube $T$. The lens $L$ forms an image of

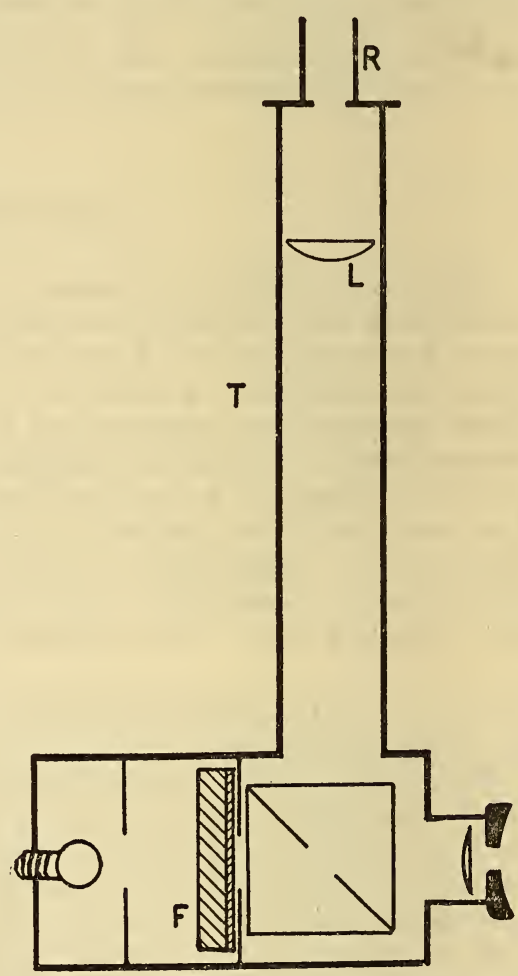

FiguRe 2.-Diagram of arrangement of optical parts of brightness meter.

the preparation on the photometer cube below. The filter is shown at $\mathrm{F}$. With a single filter in the arrangement shown, brightness of from 2 to $75 \mu \mathrm{L}$ can be measured which is a greater range than is 


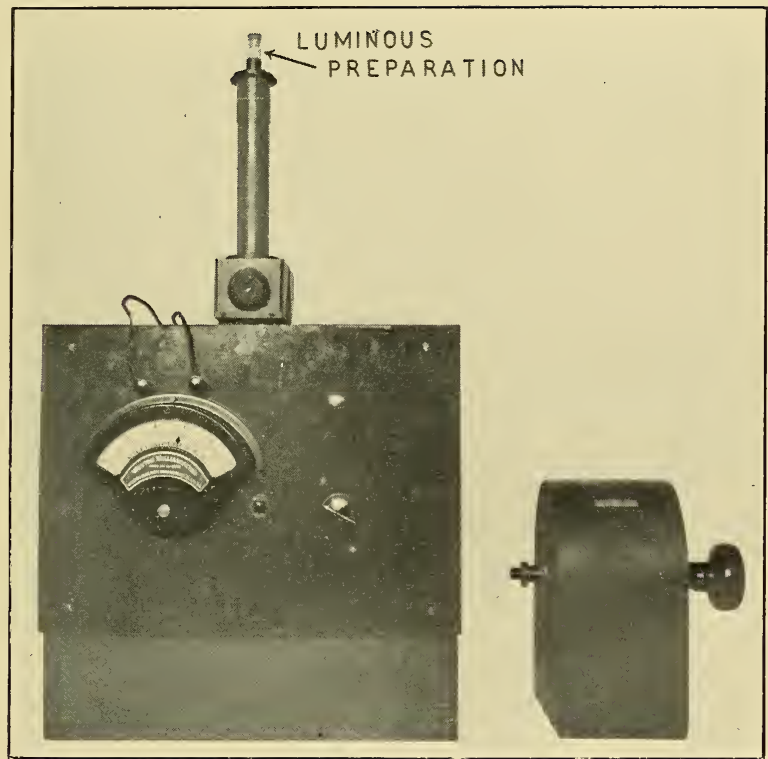

FIGURE 3.-Photograph of complete instrument with calibration scale. 
ordinarily met with in luminous samples, where the average brightness is about $20 \mu \mathrm{L}$. For calibration, a standard lamp and calibrated color filter were used to obtain settings of the milliammeter for various brightnesses. A curve was drawn and values for every half division of the milliammeter were read from the curve. These values were typed on a paper ribbon opposite the corresponding milliammeter readings so that the latter could be instantly converted into $\mu \mathrm{L}$ with sufficient accuracy. The completed instrument (left) and arrangement for converting readings into $\mu \mathrm{L}$ (right) are shown in the photograph, figure 3 .

It is to be noted that the lamp is always burned well below normal voltage which greatly prolongs its life. This is important in that a renewal of the lamp requires a calibration. Another convenient feature of the arrangement is that the short circuit switch for the milliammeter, used by Crawford, is not necessary. This is because the flashlight bulb is of a vacuum type with a filament of small heat capacity; consequently when the voltage is applied the resistance of the lamp rises so quickly from its cold value that no damage is done to the meter.

The writer wishes to acknowledge the help of Miss C. L. Torrey in calibrating the meter and of B. W. Brown in its construction.

Washington, June 11, 1934. 